\title{
Ectopic Posterior Pituitary, Polydactyly, Midfacial Hypoplasia and Multiple Pituitary Hormone Deficiency due to a Novel Heterozygous IVS11-2A>C(C.1957-2A > C) Mutation in the GLI2 Gene
}

\author{
${ }_{1}^{1}$ Gazi Yaşargil Training and Research Hospital, Clinics of Paediatric Endocrinology, Diyarbakır, Turkey \\ ${ }^{2}$ Hacettepe University Faculty of Medicine, Department of Paediatric Endocrinology, Ankara, Turkey \\ ${ }^{3}$ Gazi Yaşargil Training and Research Hospital, Clinic of Medical Genetics, Diyarbakır, Turkey \\ 4 Intergen Genetic Diagnosis Center, Clinic of Medical Genetics, Ankara, Turkey
}

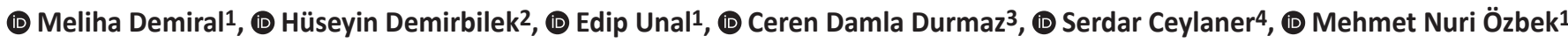

\section{What is already known on this topic?}

Patients with GLI2 mutation usually present with multiple pituitary hormone deficiency (MPHD) accompanied by ectopic posterior pituitary, polydactyly and midfacial hypoplasia. Heterozygous mutations in GLI2 cause a wide range of clinical phenotypes ranging from asymptomatic cases to more severe clinical phenotypes including Culler-Jones syndrome and holoprosencephaly (HPE) or HPE-like syndrome.

\section{What this study adds?}

A patient is reported with a novel heterozygous IVS11-2A > C(c.1957-2A > C) mutation in the GLI2 gene which expands the mutation database. Extremely distinct phenotypical expression and incomplete penetrance of heterozygous GLI2 mutations may cause MPHD to skip a generation and thus delay or missed diagnosis of these life-threatening hormonal disorders. The response to growth hormone (GH) replacement may be excellent. It is suggested that a trial of GH therapy in cases of GLI2 mutation with GH deficiency may be beneficial.

\section{Abstract}

A novel heterozygous IVS11-2A > C (c.1957-2A > C) mutation in the GLI2 gene is reported. There was an extremely distinct phenotypical expression in two siblings and their father. The index case was a boy who developed cholestasis and hypoglycaemia in the neonatal period. He had bilateral postaxial polydactyly, mid-facial hypoplasia, high palatal arch, micropenis, and bilateral cryptorchidism. Laboratory examination revealed a diagnosis of multiple pituitary hormone deficiency. There was severe anterior pituitary hypoplasia, absent pituitary stalk and ectopic posterior pituitary on magnetic resonance imaging which suggested pituitary stalk interruption syndrome with no other midline structural abnormality. Molecular genetic analysis revealed a novel heterozygous splicing IVS11-2A >C(c.1957$2 \mathrm{~A}>\mathrm{C}$ ) mutation detected in the GLI2 gene. His father and a six-year-old brother with the identical mutation also had unilateral postaxial polydactyly and mid-facial hypoplasia although there was no pituitary hormone deficiency. This novel heterozygous GLI2 mutation detected appears to present with an extremely variable clinical phenotype, even in related individuals with an identical mutation, suggesting incomplete penetrance of this GLI2 mutation.

Keywords: Growth hormone deficiency, polydactyly, GLI2 mutations, multiple pituitary hormone deficiency

\section{Introduction}

The sonic hedgehog (SHH) signalling pathway regulates differentiation, proliferation, tissue polarity, stem cell population, and carcinogenesis of the notochord and floor plate in the developing spinal cord $(1,2)$. The $\mathrm{SHH}$ signalling pathway is mediated by three related zinc-finger transcription factors (GLI1, GLI2, and GLI3) which are members of the GLI-Kruppel family. GLI2 is an activating zinc-finger transcription factor which plays a crucial role in the development of the diencephalon and distal extremities 
during embryogenesis. It is encoded by the GLI2 gene, a large polymorphic gene, that is mapped to $2 q 14.2$. Therefore, it is very likely that analysis will show variants of uncertain significance (VUS). Homozygous deletion of both GLI1 and GLI2 results in complete absence of the pituitary gland (3). Heterozygous mutations of the GLI2 gene cause a variety of clinical phenotypes, ranging from asymptomatic cases to more severe clinical phenotypes including CullerJones syndrome and holoprosencephaly (HPE) or HPE-like syndrome. Culler-Jones syndrome is a clinical spectrum of multiple pituitary hormone deficiency (MPHD), ectopic posterior pituitary, and postaxial polydactyly with or without midline defects and developmental delay (3). HPE presents with a more severe clinical spectrum with additional midline structural abnormality and forebrain cleavage defects. To date, about 25 different pathogenic GLI2 mutations have been identified (4). Heterozygous GLI2 mutations can be inherited in an autosomal dominant fashion or de novo (51\% maternal, $40 \%$ paternal, and $9 \%$ de novo) (5). Herein, we report a novel heterozygous IVS11-2A >C(c.1957$2 \mathrm{~A}>\mathrm{C}$ ) mutation in the GLI2 gene in two siblings and their father from a non-consanguineous marriage, suggesting an extremely distinct phenotypical expression and incomplete penetrance.

\section{Case Report}

\section{Index Case}

The proband was a male patient who was born after 40 weeks uneventful gestation via spontaneous vaginal delivery, with a birth weight of 3700 gr. The parents were not consanguineous. Family history revealed that one of his brothers, his father and paternal grandfather had polydactyly and atypical facial appearance with no known hormonal disorders. He had postaxial polydactyly, midfacial hypoplasia, high palatal arch, micropenis and bilateral cryptorchidism. At the age of two months, he developed cholestasis and hypoglycaemic episodes. Growth hormone $(\mathrm{GH})$, cortisol, and insulin concentrations were measured from critical blood samples which revealed a diagnosis of congenital MPHD (Table 1). Hypoglycaemia and cholestasis resolved with replacement of hydrocortisone and sodium L-thyroxine (L-T4). He had severe anterior pituitary hypoplasia, absent pituitary stalk and ectopic posterior pituitary with no other midline structural abnormality on pituitary magnetic resonance imaging (MRI). A surgical orchidopexy was performed. Diagnosis of GH deficiency was confirmed at the age of one year, and GH replacement therapy was commenced at another paediatric endocrine centre.
The patient was admitted to our hospital for the first time when he was 2.1 years old. He had been on GH replacement therapy for one year. His weight was $9 \mathrm{~kg}[-3.3$ standard deviation score (SDS)] and height was $69 \mathrm{~cm}(-5.4 \mathrm{SDS})$. During follow up at our clinic response to the GH therapy was excellent (see Figure 1). At his most recent follow-up visit when he was 10-years-old, his height was $133.5 \mathrm{~cm}(-0.46$ SDS), weight was $28.7 \mathrm{~kg}(-0.51 \mathrm{SDS})$, body mass index was

Table 1. Biochemical and hormonal characteristics of the index case and affected relatives

\begin{tabular}{|c|c|c|c|c|}
\hline & $\begin{array}{l}\text { Index } \\
\text { case } \\
\text { (two } \\
\text { months) }\end{array}$ & $\begin{array}{l}\text { Father } \\
(38 \\
\text { years) }\end{array}$ & $\begin{array}{l}\text { Brother } \\
\text { (six } \\
\text { years) }\end{array}$ & $\begin{array}{l}\text { Lab } \\
\text { normal } \\
\text { (for index } \\
\text { case) }\end{array}$ \\
\hline $\mathrm{Na}(\mathrm{mEq} / \mathrm{L})$ & 140 & 138 & 137 & $135-145$ \\
\hline $\mathrm{K}(\mathrm{mEq} / \mathrm{L})$ & 4.5 & 4.2 & 3.9 & $3.5-5.5$ \\
\hline Glu (mg/dL) & 17 & 97 & 85 & $60-100$ \\
\hline ALT (IU/L) & 24 & 38 & 44 & $0-40$ \\
\hline AST (IU/L) & 34 & 31 & 43 & $0-40$ \\
\hline GGT (IU/L) & 501 & & & $10-61$ \\
\hline $\begin{array}{l}\text { Total bilirubin } \\
\text { (mg/dL) }\end{array}$ & 6.4 & 1.1 & 0.8 & $0-1.2$ \\
\hline $\begin{array}{l}\text { Direct bilirubin } \\
(\mathrm{mg} / \mathrm{dL})\end{array}$ & 4.8 & 0.3 & 0.2 & $0-0.3$ \\
\hline LDH (IU/L) & 309 & 181 & 192 & $180-430$ \\
\hline Calcium (mg/dL) & 9.6 & 9.2 & 9.5 & $8.8-10.8$ \\
\hline $\begin{array}{l}\text { Phosphorus (mg/ } \\
\text { dL) }\end{array}$ & 5.3 & 4.1 & 3.9 & $3.5-5.5$ \\
\hline ALP (IU/L) & 940 & 110 & 147 & $150-1076$ \\
\hline Cortisol* $(\mu \mathrm{g} / \mathrm{dL})$ & 1 & 7.2 & 7.2 & $5-25$ \\
\hline $\mathrm{GH}^{*}(\mathrm{ng} / \mathrm{mL})$ & 0.059 & N/A & N/A & - \\
\hline Insulin $(\mathrm{mIU} / \mathrm{L})^{*}$ & $<2$ & N/A & N/A & - \\
\hline fT4 (ng/dL) & 0.4 & 1 & 1.25 & $0.8-1.9$ \\
\hline TSH (IU/L) & 0.84 & 2.3 & 2.16 & $0.4-8.6$ \\
\hline Prolactin (ng/mL) & 1.99 & 7 & 14.5 & $3-11$ \\
\hline $\mathrm{FSH}^{* *}(\mathrm{mIU} / \mathrm{mL})$ & 0.05 & 8 & 0.54 & $0.7-11.4$ \\
\hline $\mathrm{LH}^{* *}(\mathrm{mIU} / \mathrm{mL})$ & 0.1 & 5.2 & 0.06 & $0.8-7.6$ \\
\hline $\begin{array}{l}\text { Testosterone** } \\
\text { (ng/dL) }\end{array}$ & $<20$ & 450 & N/A & $12-21$ \\
\hline IGF1 (ng/mL) & $<25$ & 467 & 138 & 15-109 \\
\hline
\end{tabular}

*Growth hormone $(\mathrm{GH})$, cortisol and insulin were measured from critical blood sample collected during hypoglycaemia. Therefore, GH and adrenocorticotropic hormone deficiency considered due to inappropriate response.

**Gonadotropin [follicle-stimulating hormone (FSH), luteinizing hormone] and testosterone levels were considered low as these were collected during minipuberty

LH: luteinizing hormone, ALT: alanin aminotransferaz, AST: aspartat transaminaz, GGT: gamma-glutamyl transferase, LDH: lactate dehydrogenase, ALP: alkaline phosphatase, TSH: thyroid stimulating hormone, IGF1: insulin-like growth factor 1, fT4: free thyroxine, N/A: not available 
$16.1 \mathrm{~kg} / \mathrm{m}^{2}$ (-0.4 SDS). He had no signs of puberty. He had bilateral postaxial polydactyly, mid-facial hypoplasia, high palatal arch and moderate developmental delay. He was on L-T4 (2.6 $\mu \mathrm{g} / \mathrm{kg} /$ day), GH (with a dose of $0.033 \mathrm{mg} / \mathrm{kg} /$ day), hydrocortisone and antiepileptic therapy for focal epileptic seizures.

The patient's brother was six-years old with a weight of $20.7 \mathrm{~kg}(-0.01 \mathrm{SDS})$, and height was $116.2 \mathrm{~cm}$ (0.01 SDS). He had normal sized, pre-pubertal testes with no history of undescended testis. He had left postaxial polydactyly and mid-facial hypoplasia with no pituitary hormone deficiency. The patient's father was 38-years-old and his adult height was $166 \mathrm{~cm}$. He also had left postaxial polydactyly and mid-facial hypoplasia with no pituitary hormone deficiency (Table 1). Cranial MRI was not performed in the father and sibling as they had no evidence of pituitary dysfunction.

\section{Molecular Genetic Analysis}

Genomic DNA was extracted according to the manufacturer's standard procedure using the QIAamp DNA Blood Midi Kit (Qiagen, Hilden, Germany). All coding exons of the GLI2 gene and their flanking splice site junctions were amplified using in-house designed PCR primers (available upon request). These were subsequently sequenced by the MiSeq next-generation sequencing (NGS) platform (Illumina Inc., San Diego, CA, USA). The libraries were prepared with the
NexteraXT kit (Illumina Inc., San Diego, CA, USA), according to the manufacturer's instructions. Next-generation sequencing was carried on MiSeq (Illumina Inc., San Diego, CA, USA). Sequences were aligned to the hg19 genome within MiSeq Reporter software (Illumina Inc., San Diego, CA, USA). The data were visualized with IGV 2.3 (Broad Institute; http://exac.broadinstitute.org/) software. Sanger sequencing analysis was performed for confirmation of the variant detected at NGS analysis.

In silico prediction tools (MutationTaster and Human splicing finder) were used for evaluation of the novel unpublished variant. The variant was classified based on the 2015 American College of Medical Genetics and Genomics and Association for Molecular Pathology guidelines (6).

The study was conducted in accordance with the principles of the Declaration of Helsinki and was approved by the Local Ethical Committee. Written informed consent was obtained from the participants and their legal guardians.

A novel heterozygous IVS11-2A > C (c. 1957-2A > C) mutation in intron 11 of the GLI2 gene was identifid in the proband (Figure 2). His father and six-year-old brother, who both had postaxial polydactyly and facial dysmorphism with no hormonal deficiency, were also heterozygous for the identical mutation. The unaffected mother and sister had normal alleles. This variant was listed neither in the 1000 genomes

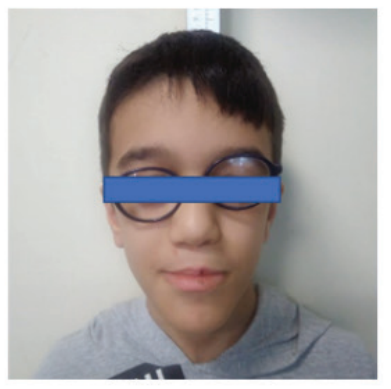

Index case (a)

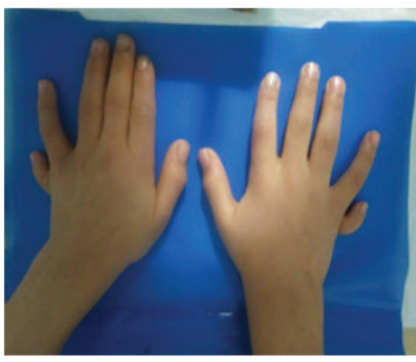

Index case(d)

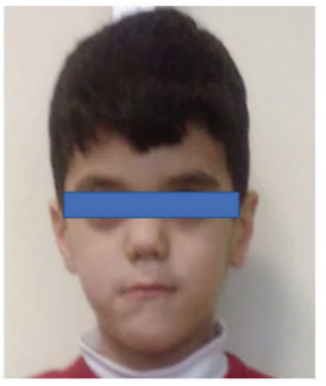

Brother (b)

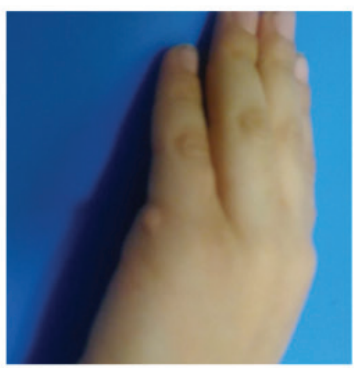

Brother (e)

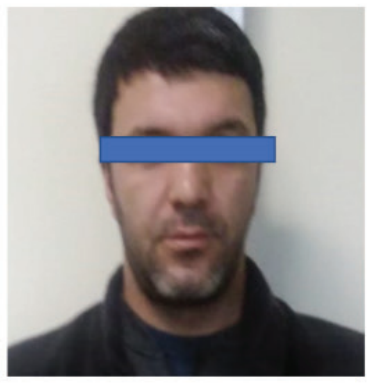

Father (c)

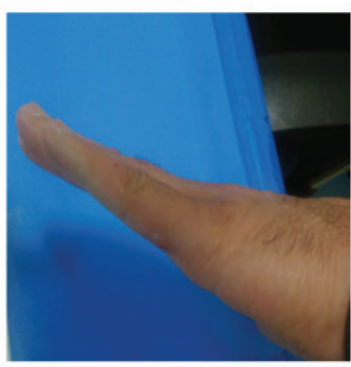

Father (f)

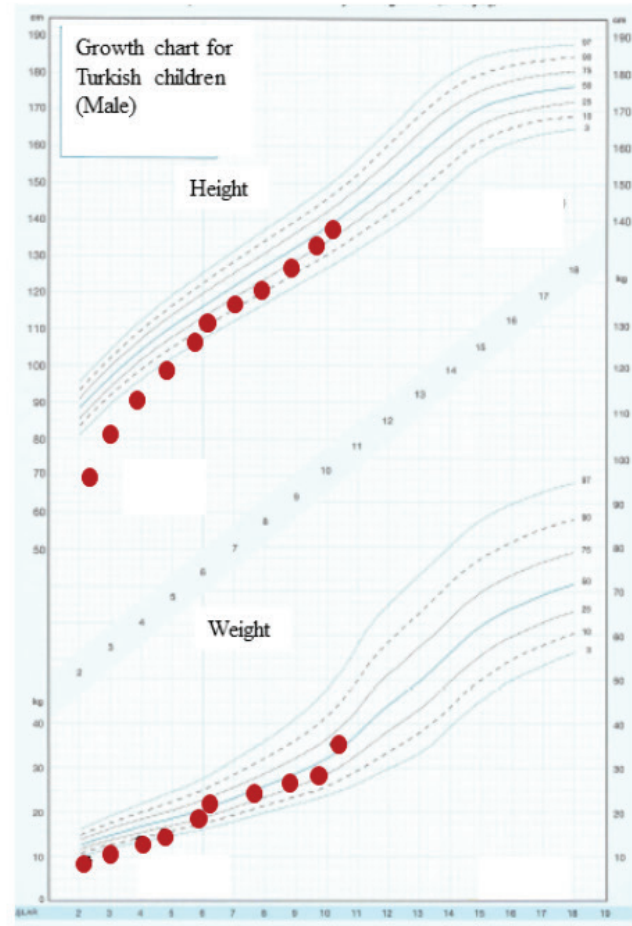

(g)

Figure 1. Facial dysmorphism and polydactyly in the index case, brother and father (a-f). Good response to recombinant human growth hormone therapy in the index case (g) 
nor in the ExAC database (http://browser.1000genomes.org/ index.html, http://exac.broadinstitute.org/, respectively). This mutation in GLI2 disrupted the intron 11 acceptor splicesite and this was predicted to result in aberrant splicing, and thus synthesis of a truncated protein.

\section{Discussion}

Herein, a patient is presented with congenital MPHD, midfacial hypoplasia, bilateral postaxial polydactyly, anterior pituitary hypoplasia and ectopic posterior pituitary due to a novel heterozygous splicing mutation IVS11-2A > C (c.1957$2 \mathrm{~A}>\mathrm{C}$ ) in the GLI2 gene. Clinical features were similar to Culler-Jones syndrome. Although his father and brother with the identical heterozygous mutation had similar physical dysmorphisms, including postaxial polydactyly and mild facial hypoplasia, they had no hormonal deficiency (Table 2).

The heterozygous IVS11-2A $>$ C (c. 1957-2A $>$ C) mutation is predicted to cause a splicing defect that would result in aberrantly spliced transcripts, and thus the synthesis of a truncated protein. GLI2 mutations leading to a truncated protein usually cause panhypopituitarism, polydactyly and midfacial hypoplasia, which were present in our index case. Interestingly, pituitary dysfunction was not detected in the proband's father and brother, both of whom had the identical mutation, suggesting incomplete penetrance and variable expressivity $(3,5,7,8)$. Distinct clinical phenotypes in subjects with identical heterozygous GLI2 mutations have previously been reported and suggested as evidence for incomplete penetrance and variable expressivity $(3,9)$. The variable expression of the GLI2 gene mutations has been attributed to the combination of genetic, environmental and epigenetic factors or contribution of the other genes involved in the SHH pathway, which include SHH, ZIC2, SIX3, PTCH1, GLI3 and TGIF genes $(5,9,10,11)$.

The largest cohort with GLI2 variants was reported by Bear et al (5) where a GLI2 variant was detected in 112 of 400 patients with HPE spectrum, endocrine disorders or craniofacial anomaly. Of these 112, 43 were found to have a truncating mutation (frameshift, nonsense, or large deletion) and 69 were reported to have a VUS (5). The clinical characteristics of cases with GLI2 mutations reported so far are shown in Table 3 (Supplementary file).

The clinical spectrum of mutations in GLI2 may vary from asymptomatic individuals to polydactyly, functional

Table 2. Clinical characteristics of index case were different from father and brother with identical GLI2 mutation and similar to Culler-Jones syndrome

\begin{tabular}{|c|c|c|c|c|}
\hline Symptoms & Index case & Father & Brother & Culler-Jones syndrome \\
\hline Mutation & $\begin{array}{l}\text { IVS11-2A > C } \\
(\text { C. } 1957-2 A>C)\end{array}$ & $\begin{array}{l}\text { IVS11-2A > C } \\
(\text { C. } 1957-2 A>C)\end{array}$ & $\begin{array}{l}\text { IVS11-2A > C } \\
(\text { C. } 1957-2 A>C)\end{array}$ & - \\
\hline Inheritance pattern & Heterozygous & Heterozygous & Heterozygous & Heterozygous \\
\hline Facial dysmorphism & + & + & + & $+1-$ \\
\hline Polydactyly & $\begin{array}{l}\text { Bilateral postaxial } \\
\text { polydactyly }\end{array}$ & $\begin{array}{l}\text { Unilateral postaxial } \\
\text { polydactyly }\end{array}$ & $\begin{array}{l}\text { Unilateral postaxial } \\
\text { polydactyly }\end{array}$ & $\begin{array}{l}\text { Unilateral/bilateral post-axial } \\
\text { polydactyly }\end{array}$ \\
\hline Cranial midline defect & - & - & - & - \\
\hline Forebrain cleavage defect & - & - & - & - \\
\hline $\begin{array}{l}\text { Anterior pituitary } \\
\text { hypoplasia }\end{array}$ & + & N/A & N/A & $+1-$ \\
\hline $\begin{array}{l}\text { Posterior pituitary } \\
\text { abnormality }\end{array}$ & $\begin{array}{l}\text { Ectopic posterior } \\
\text { pituitary }\end{array}$ & N/A & N/A & Ectopic posterior pituitary \\
\hline Pituitary stalk & Interrupted & N/A & N/A & +1 \\
\hline GH deficiency & + & - & - & $+1-$ \\
\hline TSH deficiency & + & - & - & $+1-$ \\
\hline ACTH deficiency & + & - & - & $+1-$ \\
\hline Gonadotropin deficiency & + & - & - & +1 \\
\hline Prolactin deficiency & + & - & - & +1 \\
\hline ADH deficiency & - & - & - & $+1-$ \\
\hline $\begin{array}{l}\text { Genitourinary system } \\
\text { abnormality }\end{array}$ & $\begin{array}{l}\text { Micropenis, } \\
\text { cryptorchidism }\end{array}$ & - & - & $+1-$ \\
\hline Developmental delay & + & - & - & +1 \\
\hline
\end{tabular}




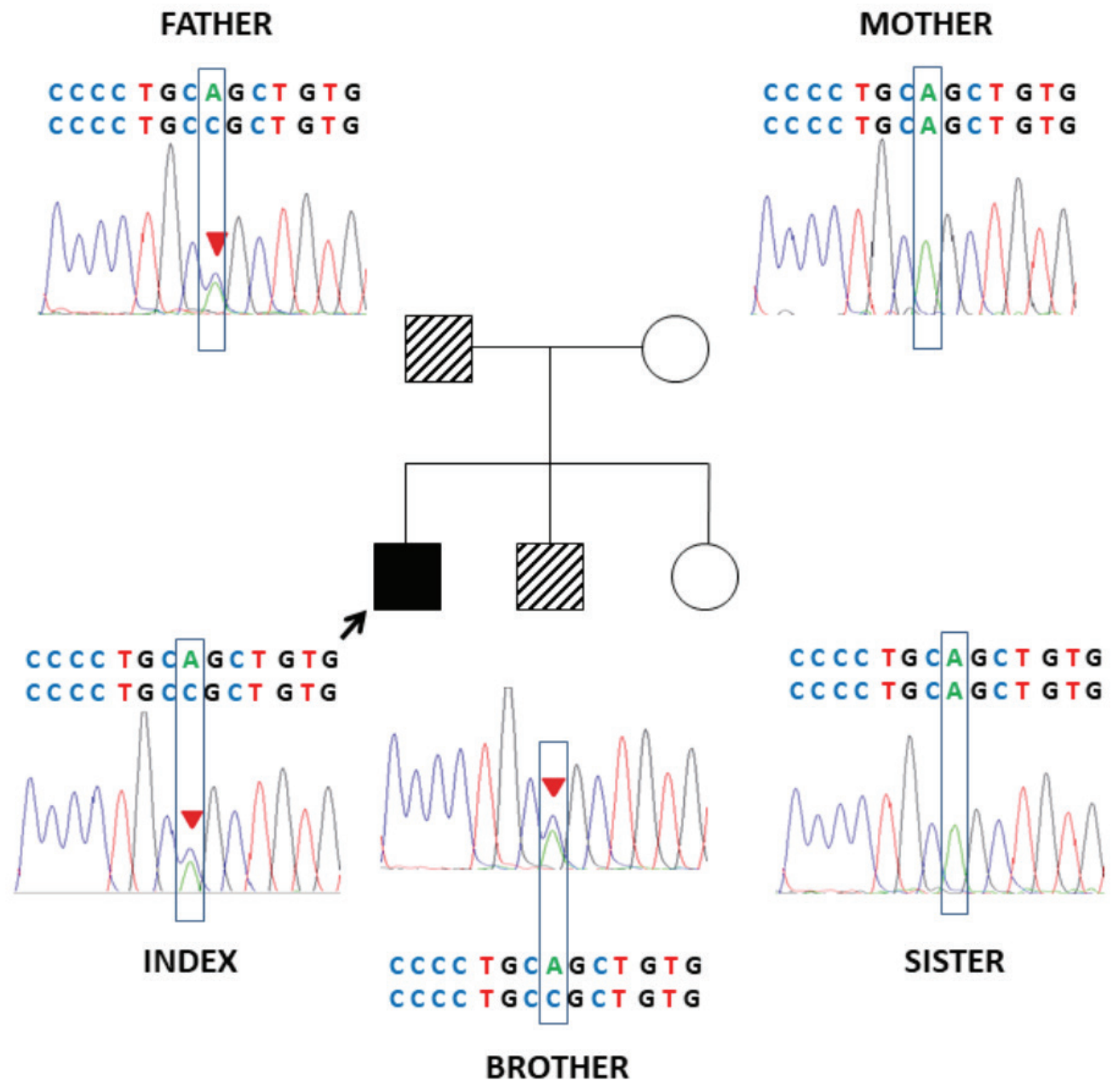

Figure 2. Family pedigree and electropherogram of heterozygous IVS11-2A > C(C.1957-2A > C) mutation in the GLI2 gene. Full-black filled box indicates index case with Culler-Jones syndrome phenotype, shaded boxes indicate father and brother who are also heterozygous for the identical mutation with incomplete phenotype, empty boxes indicate mother and sister with wild type

and structural abnormality in the pituitary gland, facial dysmorphism, Culler-Jones syndrome, HPE-like syndrome, and frank HPE $(4,8)$. In addition, renal problems such as renal hypoplasia/dysplasia, urethral stricture and cardiac problems such as ASD/VSD have been reported in patients with GLI2 mutations $(4,8)$. HPE is the most common anterior brain anomaly and HPE is characterized by incomplete separation of cerebral hemispheres and underdeveloped midbrain structures. However, the mutations in GLI2 are rarely associated with an HPE phenotype $(7,12)$. Indeed, in the study of Bear et al (5) only three of the 112 (2.7\%) patients with GLI2 mutations, had HPE (13). Also, neuroanatomical anomalies, such as agenesis of the corpus callosum, abnormal cerebral periventricular venous system and abnormal gyri have been reported in patients with GLI2 mutations $(8,14,15,16,17)$. In contrast to the literature, our patient had severe anterior pituitary hypoplasia, MPHD, and ectopic posterior pituitary with no features of HPE or HPE like syndrome. Pituitary stalk interruption syndrome (PSIS) is a congenital anomaly of the pituitary gland characterized by small or absent anterior pituitary lobe, interrupted or absent pituitary stalk, and ectopic posterior pituitary lobe (18). PSIS may be associated with isolated or syndromic features (18). Mutations in genes encoding transcription factors in signalling pathways, especially GLI2 variants, have been reported in PSIS, which is consistent with our case $(18,19)$.

Pituitary dysfunction due to GLI2 mutations may vary from idiopathic GH deficiency to MPHD, with or without ADH deficiency $(3,5)$. Our index case had biochemical and hormonal features of complete anterior pituitary hormone deficiency including $\mathrm{GH}$, thyroid-stimulating hormone, 


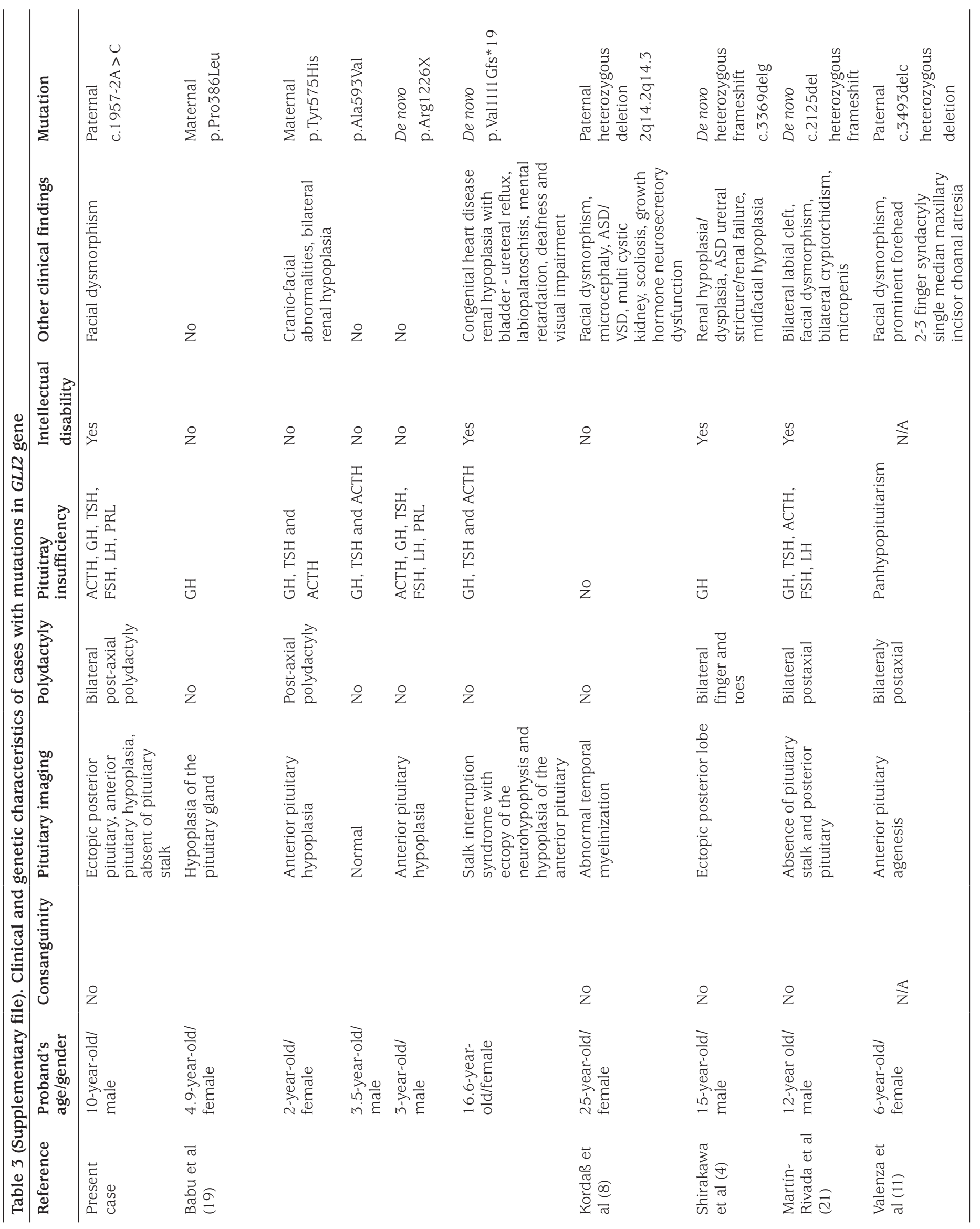




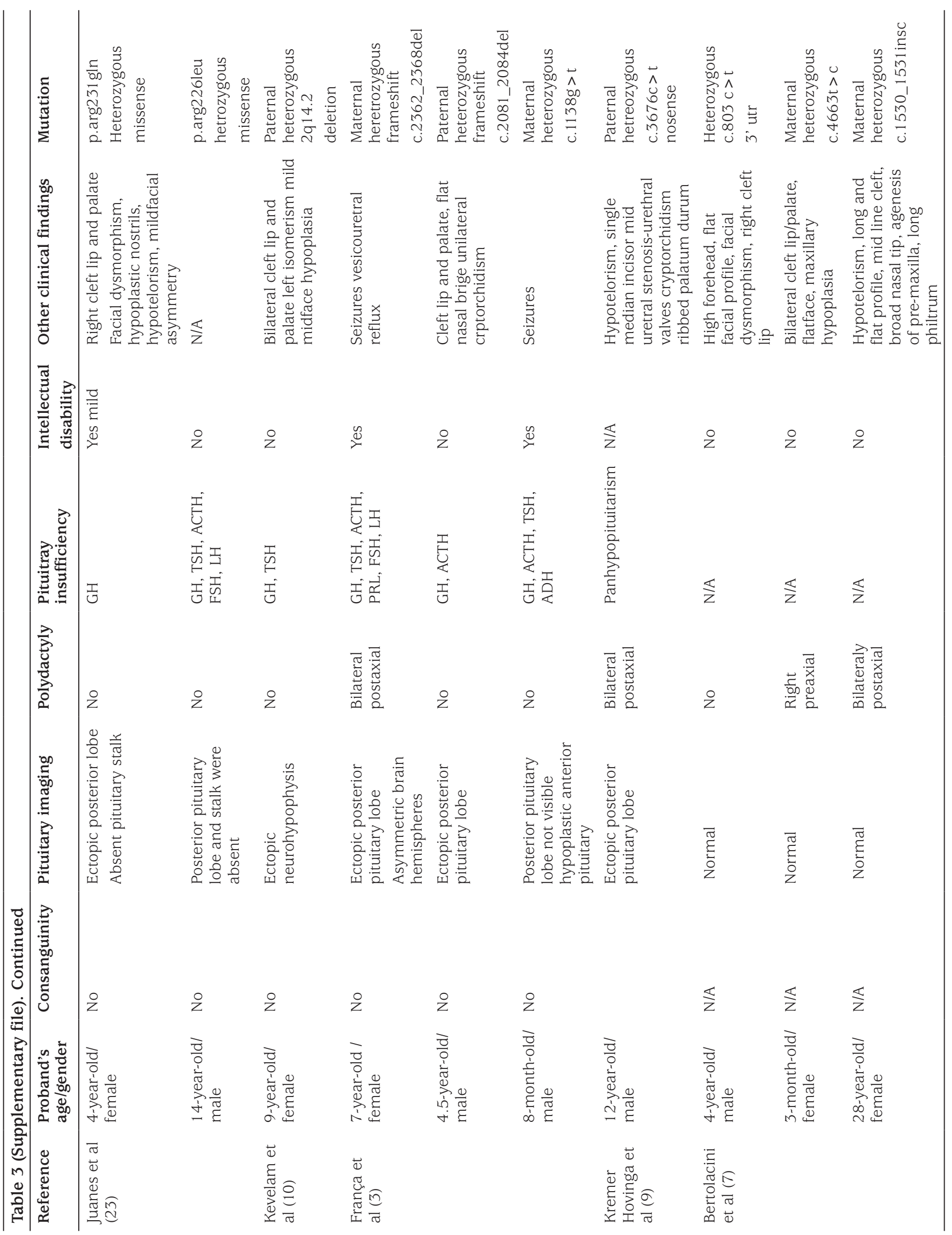




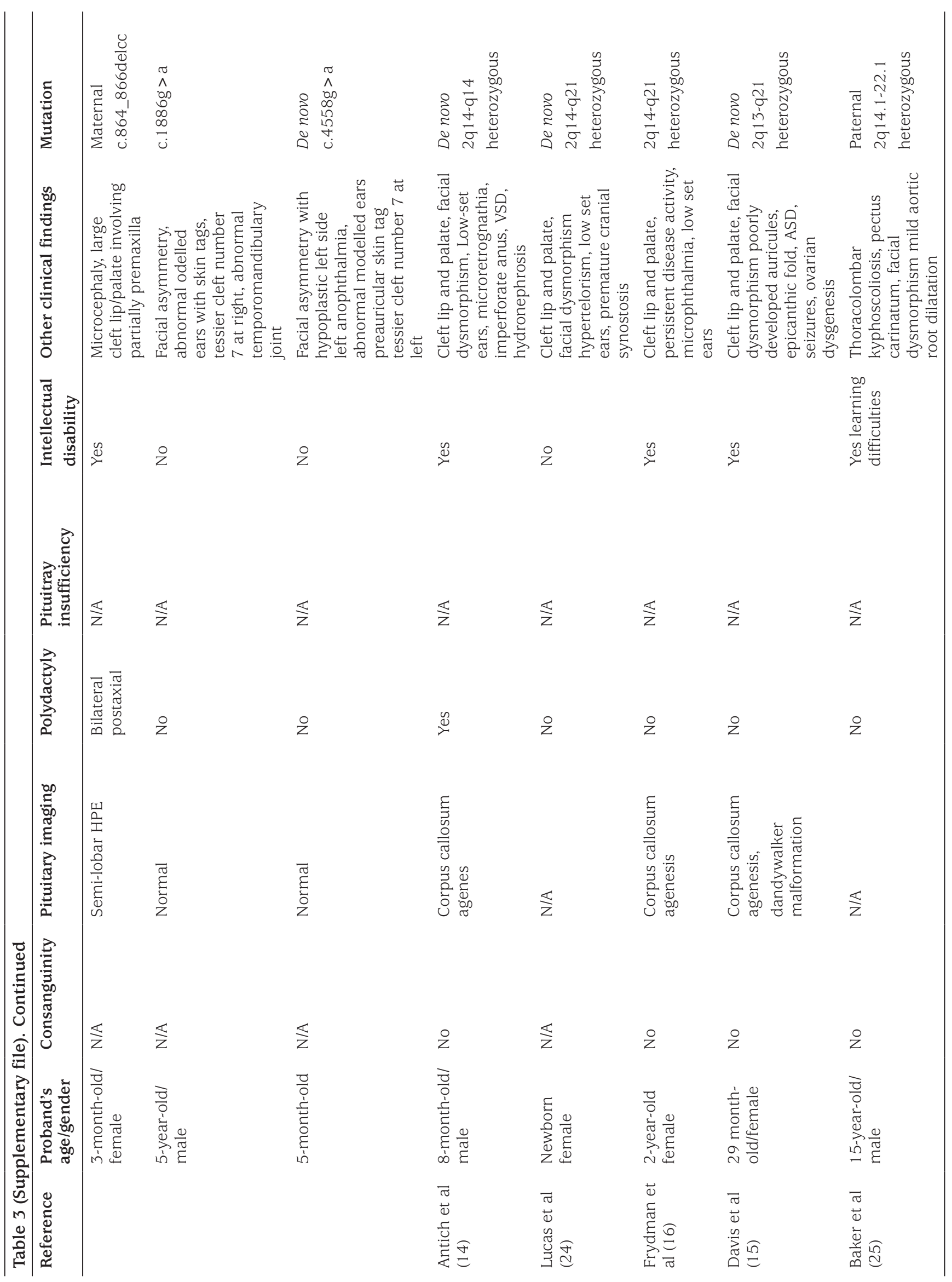


adrenocorticotropic hormone (ACTH), prolactin, follicle-stimulating hormone (FSH) and Luteinizing hormone (LH) (Table 1). The most common pituitary hormone deficiency is GHD (20). Although the response to rhGH replacement has been reported to be poor in some cases with GLI2 mutations, an excellent response to rhGH replacement was observed in our case and has been reported previously. This suggests that clinicians should consider a trial of rhGH therapy in cases with GLI2 mutation who have GHD (Figure 1) $(3,8,21)$. In addition, hypoglycaemia, cholestasis, recurrent seizures and intellectual disability have been reported in patients with GLI2 mutations as a consequence of ACTH and GH deficiency (22). Hypoglycaemic episodes and cholestasis in our case resolved after replacement of hydrocortisone and with rhGH therapy. We also attributed the seizures and moderate developmental delay evident in our case to neonatal hypoglycaemic episodes due to ACTH and GH deficiency. While the presence of micropenis in our case may be attributed to GH deficiency, he also had cryptorchidism and inappropriately low FSH, LH and testosterone levels during mini-puberty, suggesting concomitant gonadotropin deficiency. Despite having an ectopic posterior pituitary on pituitary-imaging he had no diabetes insipidus at presentation and this has not developed to date during follow-up.

\section{Conclusion}

In conclusion, extra-pituitary findings may provide clues for the diagnosis of particular gene mutations including GLI2, HESX1, LHX4, SOX3, and OTX2 which are involved in the development and differentiation of the pituitary gland resulting in a variety of pituitary hormone deficiencies. In cases presenting with MPHD accompanied by ectopic posterior pituitary, polydactyly and midfacial hypoplasia, a diagnosis of GLI2 mutation should be considered. Furthermore, extremely distinct phenotypical expression and incomplete penetrance of heterozygous GLI2 mutations may be associated with MPHD skipping a generation and thus delay or missed diagnosis of these life-threatening hormonal disorders. In light of this genetic analysis of either asymptomatic or symptomatic relatives for GLI2 gene mutations and evaluation of carriers for panhypopituitarism is warranted.

\section{Ethics}

Informed Consent: The subject and his parents have given their written informed consent to publish their case, in accordance with the Declaration of Helsinki.

Peer-review: Externally and internally peer-reviewed.

\section{Authorship Contributions}

Concept: Meliha Demiral, Hüseyin Demirbilek, Mehmet Nuri Özbek, Design: Meliha Demiral, Hüseyin Demirbilek, Mehmet Nuri Özbek, Data Collection or Processing: Meliha Demiral, Hüseyin Demirbilek, Mehmet Nuri Özbek, Analysis or Interpretation: Meliha Demiral, Edip Ünal, Ceren Damla Durmaz, Serdar Ceylaner, Literature Search: Meliha Demiral, Edip Ünal, Writing: Meliha Demiral, Hüseyin Demirbilek, Mehmet Nuri Özbek.

Financial Disclosure: The authors declared that this study received no financial support. 


\section{References}

1. Haddad-Tóvolli R, Paul FA, Zhang Y, Zhou X, Theil T, Puelles L, Blaess S, Alvarez-Bolado G. Differential requirements for Gli2 and Gli3 in the regional specification of the mouse hypothalamus. Front Neuroanat 2015;9:34

2. Yang C, Li S, Li X, Li H, Li Y, Zhang C, Lin J. Effect of sonic hedgehog on motor neuron positioning in the spinal cord during chicken embryonic development. J Cell Mol Med 2019;23:3549-3562. Epub 2019 Mar 4

3. França MM, Jorge AA, Carvalho LR, Costalonga EF, Vasques GA, Leite $\mathrm{CC}$, Mendonca BB, Arnhold IJ. Novel heterozygous nonsense GLI2 mutations in patients with hypopituitarism and ectopic posterior pituitary lobe without holoprosencephaly. J Clin Endocrinol Metab 2010;95:384-391. Epub 2010 Aug 4

4. Shirakawa T, Nakashima Y, Watanabe S, Harada S, Kinoshita M, Kihara T, Hamasaki Y, Shishido S, Yoshiura KI, Moriuchi H, Dateki S. A novel heterozygous GLI2 mutation in a patient with congenital urethral stricture and renal hypoplasia/dysplasia leading to end-stage renal failure. CEN Case Rep 2018;7:94-97. Epub 2018 Jan 9

5. Bear KA, Solomon BD, Antonini S, Arnhold IJ, França MM, Gerkes EH, Grange DK, Hadley DW, Jääskeläinen J, Paulo SS, Rump P, Stratakis CA, Thompson EM, Willis M, Winder TL, Jorge AA, Roessler E, Muenke $M$. Pathogenic mutations in GLI2 cause a specific phenotype that is distinct from holoprosencephaly. J Med Genet 2014;51:413-418. Epub 2014 Apr 17

6. Richards S, Aziz N, Bale S, Bick D, Das S, Gastier-Foster J, Grody WW, Hegde M, Lyon E, Spector E, Voelkerding K, Rehm HL; ACMG Laboratory Quality Assurance Committee. Standards and guidelines for the interpretation of sequence variants: a joint consensus recommendation of the American College of Medical Genetics and Genomics and the Association for Molecular Pathology. Genet Med 2015;17:405-424. Epub 2015 Mar 5

7. Bertolacini CD, Ribeiro-Bicudo LA, Petrin A, Richieri-Costa A, Murray JC. Clinical findings in patients with GLI2 mutations--phenotypic variability. Clin Genet 2012;81:70-75. Epub 2011 Jan 19

8. Kordaß U, Schröder C, Elbracht M, Soellner L, Eggermann T. A familial GLI2 deletion (2q14.2) not associated with the holoprosencephaly syndrome phenotype. Am J Med Genet A 2015;167:1121-1124. Epub 2015 Mar 28

9. Kremer Hovinga ICL, Giltay JC, van der Crabben SN, Steyls A, van der Kamp HJ, Paulussen ADC. Extreme phenotypic variability of a novel GLI2 mutation in a large family with panhypopituitarism and polydactyly: clinical implications. Clin Endocrinol (Oxf) 2018;89:378380. Epub 2018 Jul 3

10. Kevelam SH, van Harssel JJ, van der Zwaag B, Smeets HJ, Paulussen AD, Lichtenbelt KD. A patient with a mild holoprosencephaly spectrum phenotype and heterotaxy and a 1.3 Mb deletion encompassing GLI2. Am J Med Genet A 2012;158:166-173. Epub 2011 Nov 21

11. Valenza F, Cittaro D, Stupka E, Biancolini D, Patricelli MG, Bonanomi D, Lazarević D. A novel truncating variant of GLI2 associated with Culler-Jones syndrome impairs Hedgehog signalling. PloS One 2019;14:e0210097.

12. Heyne GW, Everson JL, Ansen-Wilson LJ, Melberg CG, Fink DM, Parins KF, Doroodchi P, Ulschmid CM, Lipinski RJ. Gli2 geneenvironment interactions contribute to the etiological complexity of holoprosencephaly: evidence from a mouse model. Dis Model Mech 2016;9:1307-1315. Epub 2016 Sep 1
13. Kurtoğlu S, Özdemir A, Hatipoğlu N. Neonatal Hypopituitarism: Approaches to Diagnosis and Treatment. J Clin Res Pediatr Endocrinol 2019;11:4-12. Epub 2018 May 9

14. Antich J, Carbonell X, Mas J, Clusellas N. De novo interstitial deletion of the long arm of chromosome 2 in a malformed newborn with a karyotype: 46,XY,del(2)(q12q14). Acta Paediatr Scand 1983;72:631633.

15. Davis E, Grafe M, Cunniff C, Jones KL, Bogart M. Interstitial deletion of chromosome $2 \mathrm{q}$ associated with ovarian dysgenesis. Clin Genet 1991;39:386-390

16. Frydman M, Cohen HA, Ashkenazi A, Varsano I. Familial segregation of cervical ribs, Sprengel anomaly, preaxial polydactyly, anal atresia, and urethral obstruction: a new syndrome? Am J Med Genet 1993;45:717720.

17. Peng HH, Wang CJ, Wang TH, Chang SD. Prenatal diagnosis of de novo interstitial $2 q 14.2-2 q 21.3$ deletion assisted by array-based comparative genomic hybridization: a case report. J Reprod Med 2006;51:438-442.

18. waveling-Soonawala N, Alders M, Jongejan A, Kovacic L, Duijkers FA, Maas SM, Fliers E, van Trotsenburg ASP, Hennekam RC. Clues for Polygenic Inheritance of Pituitary Stalk Interruption Syndrome From Exome Sequencing in 20 Patients. J Clin Endocrinol Metab 2018;103:415-428.

19. Babu D, Fanelli A, Mellone S, Muniswamy R, Wasniewska M, Prodam F, Petri A, Bellone S, Salerno MC, Giordano M. Novel GLI2 mutations identified in patients with Combined Pituitary Hormone Deficiency (CPHD): Evidence for a pathogenic effect by functional characterization. Clin Endocrinol (Oxf) 2019;90:449-456. Epub 2019 Jan 7

20. Arnhold IJ, França MM, Carvalho LR, Mendonca BB, Jorge AA. J Mol Endocrinol 2015;54:141-150. Epub 2015 Apr 15

21. Martín-Rivada Á, Rodríguez-Contreras FJ, Muñoz-Calvo MT, Güemes M, González-Casado I, Del Pozo JS, Campos-Barros Á, Argente J. A novel GLI2 mutation responsible for congenital hypopituitarism and polymalformation syndrome. Growth Horm IGF Res 2019;44:17-19. Epub 2018 Dec 18

22. Wada K, Kobayashi H, Moriyama A, Haneda Y, Mushimoto Y, Hasegawa Y, Onigata K, Kumori K, Ishikawa N, Maruyama R, Sogo T, Murphy L, Taketani T. A case of an infant with congenital combined pituitary hormone deficiency and normalized liver histology of infantile cholestasis after hormone replacement therapy. Clin Pediatr Endocrinol 2017;26:251-257

23. Juanes M, Di Palma I, Ciaccio M, Marino R, Ramírez PC, Pérez Garrid N, Maceiras M, Lazzati JM, Rivarola MA, Belgorosky A. Two novel heterozygous missense variations within the GLI2 gene in two unrelated Argentine patients. Medicina 2016;76:213-218.

24. Lucas J, Faivre J, Le Mee F, Hubert S, Pluquailec K, Picard F. [De novo interstitial deletion of the long arm of chromosome 2: 46,XXX,del(2) (q14q21), associated with premature craniosynostosis]. Ann Genet 1987;30:33-38.

25. Baker E, Hinton L, Callen DF, Haan EA, Dobbie A, Sutherland GR. A familial cryptic subtelomeric deletion $12 p$ with variable phenotypic effect. Clin Genet 2002;61:198-201.

26. Gustavsson P, Schoumans J, Staaf J, Jönsson G, Carlsson F, Kristoffersson U, Borg A, Nordenskjöld M, Dahl N. Hemizygosity for chromosome 2q14.2-q22.1 spanning the GLI2 and PROC genes associated with growth hormone deficiency, polydactyly, deep vein thrombosis and urogenital abnormalities. Clin Genet 2006;69:441-443. 